\title{
Antibodies recognizing a variety of different structural motifs on meningococcal Lip antigen fail to demonstrate bactericidal activity
}

\author{
Colin R. Tinsley, $\dagger$ Mumtaz Virji $\ddagger$ and John E. Heckels* \\ Department of Microbiology, Southampton University Medical School, Southampton General Hospital, Tremona Road, \\ Southampton SO9 $4 X Y, U K$
}

(Received 12 March 1992; revised 3 August 1992; accepted 12 August 1992)

\begin{abstract}
The neisserial Lip antigen is a conserved antigen associated with the pathogenic Neisseria species, and is composed of multiple repeats of a consensus pentapeptide. A series of monoclonal antibodies reacting with meningococcal Lip antigen were subjected to epitope mapping, using solid-phase synthetic peptides based on the consensus repeat sequence. The antibodies were found to recognize different continuous epitopes based on the consensus sequence. One monoclonal antibody was utilized in affinity chromatography to obtain purified Lip antigen and the antigen was used for immunization of mice. The resulting antisera did not recognize Lip antigen on Western blots but reacted specifically with Lip antigen in immune precipitation experiments, indicating that the predominant polyclonal immune response was directed against conformational epitopes. Despite the diversity of both continuous and conformational epitopes recognized by the antibodies produced, none of the antibodies demonstrated the ability to promote complement-mediated bactericidal activity. Thus despite its initial apparent promise as a potential vaccine candidate the case for the inclusion of $\mathrm{Lip}$ antigen in vaccine formulation cannot be supported at present.
\end{abstract}

\section{Introduction}

Disease due to Neisseria meningitidis remains an important cause of morbidity and mortality. While purified capsular polysaccharide is used in immunoprophylaxis against disease caused by serogroups A, C, Y and W135 (Peltola et al., 1985), these vaccines provide little protection in infants and young children (Gold et al., 1979; Reingold et al., 1985), the age group who are most susceptible to attack (Goldschneider et al., 1969). Furthermore, there is currently no polysaccharide vaccine against organisms of serogroup $B$, the most common cause of epidemic meningococcal disease in the USA and Europe (Peltola, 1983).

The shortcomings of polysaccharide vaccines have led to the investigation of other surface antigens such as outer-membrane proteins, lipopolysaccharide (LPS) and

* Author for correspondence. Tel. +44703 796974; fax +44704 774316; e-mail JEH@UK.AC.SOUTHAMPTON.MAIL.

$\dagger$ Present address: Department of Microbiology and Immunology, Rockefeller University, New York, USA.

$\ddagger$ Present address: University of Oxford Department of Paediatrics, John Radcliffe Hospital, Oxford, UK.

Abbreviation: mAb, monoclonal antibody. pili as vaccine candidates. Meningococcal outer membranes contain four classes of outer-membrane proteins, named 1, 2 or 3, 4 and 5 in order of decreasing apparent molecular mass on SDS-PAGE. Although these proteins are immunogenic during disease and after vaccination (Poolman et al., 1983; Wedege \& Froholm, 1986) attempts at the use of the outer-membrane proteins for immunoprophylaxis have been hampered by their antigenic diversity. The class 5 proteins and pili are subject to inter-strain antigenic variation during the course of an infection (Poolman et al., 1980; Tinsley \& Heckels, 1986) while the class $2 / 3$ and class 1 proteins show differences between strains that are responsible for serotype and subtype differences respectively (Frasch $e t$ al., 1985). The ideal of a meningococcal vaccine that would stimulate immunity to a wide variety of antigenically distinct strains focuses attention on more conserved surface antigens.

One such candidate, the highly conserved class 4 protein, has recently been shown to be capable of inducing 'blocking' antibodies which are not only nonbactericidal but also inhibit the bactericidal effect of antibodies directed against other surface antigens (Munkley et al., 1991). Such antibodies would therefore be expected to be antagonistic to vaccine development. 
Using a monoclonal antibody (H.8) raised against gonococcal outer membranes Cannon et al. (1984) reported the detection of a surface-exposed determinant, of apparent molecular mass $20 \mathrm{kDa}$, which was common to all pathogenic neisseriae and absent from most nonpathogenic species. This antigen, initially termed H.8 antigen, although readily detected on Western blots could not be detected by staining following SDS-PAGE. An antigen with similar properties but varying in apparent molecular mass between 18 and $30 \mathrm{kDa}$ was subsequently reported by two other groups (Virji et al., 1985; Zollinger et al., 1985). Subsequent biochemical and genetic studies have identified the $\mathrm{H} .8$ antigen as a lipoprotein, based on multiple imperfect repeats of a consensus pentapeptide lacking aromatic amino acids (Baehr et al., 1989; Woods et al., 1989). As a result of its lipoprotein nature the antigen has been formally designated as Lip, the product of the lip gene (Hitchcock, 1989).

The Lip antigen's conservation, its association with pathogenic species and immunogenicity during gonococcal and meningococcal disease (Black et al., 1985) has led to interest in its potential as a component of an antiNeisseria vaccine. However, limited data are available on the potential protective effect of antibodies directed against Lip antigen and some of the results reported are contradictory. One report found passive protection against experimental meningococcal infection by the H. 8 anti-Lip mAb (Black \& Cannon, 1984). More recent studies report that one anti-Lip mAb may promote complement-mediated killing of some gonococcal strains (Schweinle et al., 1989), while another is ineffective against meningococcal strains (Bhattacharjee et al., 1990).

In order to investigate the potential of the Lip antigen as a vaccine component, mAbs recognizing distinct epitopes on the antigen have been examined for their potential bactericidal effect on meningococci. In addition the Lip antigen has been purified and used to elicit polyclonal antisera, whose specificity and bactericidal activity have been compared to those of the mAbs.

\section{Methods}

Bacterial strains and growth conditions. Neisseria meningitidis strain MC50 (group C, non-typable, subtype P1.16) was from the cerebrospinal fluid of a patient with meningococcal meningitis. Isolation and subsequent culture conditions have been described previously (Tinsley \& Heckels, 1986).

Monoclonal antibodies. mAbs reactive with Lip antigen obtained following immunization of mice with outer membranes from Neisseria gonorrhoeae strain P9 were SM70 ( $\gamma 2 \mathrm{~b}), \operatorname{SM} 71(\gamma 1), \operatorname{SM} 72(\gamma 3)$ and SM73 $(\gamma 3)$ (Virji \& Heckels, 1988). The mAb SM300 ( $\gamma 2 b)$, directed against the P1.16 epitope on meningococcal class 1 protein, was obtained following immunization with outer membranes of strain MC50 (McGuinness et al., 1991). The ascites fluids used all contained between 4 and $6 \mathrm{mg} \mathrm{IgG} \mathrm{ml}^{-1}$.

SDS-PAGE and Western blotting. SDS-PAGE was carried out on gels containing a linear gradient of $10-25 \%(w / v)$ acrylamide gradient as described previously (Heckels, 1981). Proteins were visualized by staining with PAGE-Blue 83, carried out as described by Fairbanks $e t$ al. (1971), or by silver staining performed according to the method of Hitchcock \& Brown (1983).

For Western blotting after electrophoretic separation of cell components by SDS-PAGE, gels were soaked for $30 \mathrm{~min}$ in $20 \mathrm{~mm}-$ Tris, pH 10.4, containing $20 \%$ (v/v) methanol. Electrophoretic transfer of antigens to nitrocellulose was carried out with a 'Semi-dry multi-gel electroblotter' (Ancos, Denmark) using the method of Khyse-Andersen (1984). Immune detection of electrophoretically transferred antigens was carried out with ${ }^{125}$ I-Protein $A$ as described previously (Tinsley \& Heckels, 1986).

Immune precipitation reaction. Non-radioactive immune precipitation was based on the radio-immune precipitation assay of Diaz et al. (1984). Meningococci were suspended in PBS containing $0.3 \%$ Empigen BB (Albright \& Wilson, Cumbria) and $0 \cdot 1 \%$ SDS (RIP buffer) for $2 \mathrm{~h}$ at $37^{\circ} \mathrm{C}$, then the insoluble material was removed by centrifugation at $100000 \mathrm{~g}$ for $30 \mathrm{~min}$. The soluble antigen $(80 \mu \mathrm{g}$ protein in $100 \mu \mathrm{l}$ ) was mixed with $40 \mu \mathrm{l}$ of a $1 / 10$ dilution of either ascitic fluid containing $\mathrm{mAb}$ or polyclonal antiserum, together with a suspension $(50 \mu \mathrm{l})$ of agarose-linked goat anti-mouse IgG (Sigma). The mixture was incubated at $4{ }^{\circ} \mathrm{C}$ for $1.5 \mathrm{~h}$ with end-over-end rotation. The beads were recovered by centrifugation, washed with RIP buffer then boiled in SDS-PAGE dissociating buffer to solubilize the precipitated antigen, which was then subjected to SDS-PAGE. The identity of the precipitated antigens was determined by Western blotting with appropriate antisera.

Analytical techniques. (i) Measurement of protein concentration. Protein concentrations were measured by the Lowry method or by the more sensitive micro-bicinchoninic acid (micro-BCA, Pierce) assay (Smith et al., 1985).

(ii) Quantitative dot-blot analysis for the Lip antigen. Samples containing the antigen in solution were serially diluted into PBS and samples $(3 \mu \mathrm{l})$ from each dilution were applied to a sheet of nitrocellulose. Non-specific protein binding was blocked by incubation in BSA solution, and the nitrocellulose was incubated with anti-Lip $\mathrm{mAb}$ followed by ${ }^{125} \mathrm{I}$-Protein $\mathrm{A}$ as for Western blotting. Equal-sized squares containing each spot of antigen were cut from the nitrocellulose and bound radioactivity was measured by a gamma counter. For each sample the bound radioactivity was plotted against $\log$ (dilution), to give a graph similar to that obtained from a conventional ELISA and allowing comparison of the concentrations of antigen in different samples. The absolute amount of antigen present was subsequently calculated by comparison with a known amount of purified Lip antigen.

(iii) Amino acid analysis. Samples containing between 0.5 and $2 \mu \mathrm{g}$ of protein or a standard mixture of amino acids were hydrolysed by vapour-phase $\mathrm{HCl}$ at $110^{\circ} \mathrm{C}$ in an evacuated vessel for $24 \mathrm{~h}$. Analysis was carried out using an 'amino-chrome' kit (Ciba Corning) in which the amino acids were reacted with dabsylation reagent then separated by reverse-phase HPLC according to the manufacturer's instructions.

(iv) $N$-terminal sequence analysis of purified Lip antigen. Purified antigen $(20 \mu \mathrm{g}$ protein) was dissolved in trifluoroacetic acid and subjected to $\mathrm{N}$-terminal sequence analysis using an Applied Biosystems 477A pulsed liquid-phase protein sequencer with on-line PTH amino acid identification.

Epitope mapping with solid-phase oligopeptides. Oligopeptides corresponding to the inferred sequence of the Lip antigen (Baehr et al., 1989) 
were synthesized on polyethylene pins using a commercially available kit (CRB, Cambridge) and pentafluorophenyl active esters of fluorenylmethoxycarbonyl-L-amino acids (Milligen) as described previously (Virji \& Heckels, 1989). Immunological reactivity of the peptides was assayed by ELISA as previously described and was always observed with duplicate peptides.

In vitro, complement-mediated bactericidal assay. The procedure used was as described by Munkley at al. (1991). Meningococci were harvested after $19 \mathrm{~h}$ growth, centrifuged for $2 \mathrm{~min}$ at $60 \mathrm{~g}$ to remove aggregates of cells and diluted in PBSB (Difco) containing $1 \%(\mathrm{w} / \mathrm{v})$ decomplemented foetal calf serum (Gibco). The complement source was guinea-pig serum (Gibco) at a final concentration of $10 \%(\mathrm{v} / \mathrm{v})$. The suspensions were incubated with serial dilutions of antibody at $37^{\circ} \mathrm{C}$ for $30 \mathrm{~min}$. The bactericidal activities of each dilution of antibody were expressed as the percentage killing, defined as [ $1-$ number of survivors in wells containing complement divided by number of survivors in wells containing decomplemented serum $\}] \times 100$.

Affinity chromatography. The anti-Lip mAb SM70 was purified from murine ascitic fluid by HPLC on a hydroxyapatite column (HPHT; Bio-Rad) using a linear gradient of $10-350 \mathrm{~mm}$-sodium phosphate buffer, pH 6.8, as described previously (Virji et al., 1987). The purified immunoglobulin $(10 \mathrm{mg})$ was dialysed against $0.1 \mathrm{M}$-sodium bicarbonate, $\mathrm{pH} 8.3$, containing $0.5 \mathrm{M}$-sodium chloride and was coupled to $0.86 \mathrm{~g} \mathrm{CNBr}$-activated Sepharose CL4B (Pharmacia) using the manufacturer's recommended procedure.

Meningococcal cells were solubilized by incubation in RIP buffer at $37^{\circ} \mathrm{C}$ for $2 \mathrm{~h}$, since this treatment had been found to solubilize almost all of the antigen, and it was known not to disrupt antibody-antigen interactions (Zak et al., 1983). Solubilized antigen containing $40 \mathrm{mg}$ whole-cell protein was applied to the affinity column in a total volume of $18 \mathrm{ml}$. Unbound material was removed by extensive washing with $\mathrm{RIP}$ buffer, then the column was eluted with $0.5 \mathrm{M}-\mathrm{NaCl}$ adjusted to $\mathrm{pH} 11.0$ with $\mathrm{NH}_{4} \mathrm{OH}$. The eluted fractions were immediately neutralized by gassing with $\mathrm{CO}_{2}$ until the $\mathrm{pH}$ fell below 8.0.

Production of anti-Lip polyclonal antisera. Affinity-purified antigen was adsorbed to aluminium hydroxide gel (Alhydrogel; Superphos, Denmark) by incubation at $4{ }^{\circ} \mathrm{C}$ for $16 \mathrm{~h}$. Mice were initially immunized intraperitoneally with $2-10 \mu \mathrm{g}$ purified antigen adsorbed to $250 \mu \mathrm{g}$ Alhydrogel followed by four booster immunizations at intervals of approximately two weeks. Controls were similarly immunized with Alhydrogel alone.

\section{Results}

\section{Properties of anti-Lip monoclonal antibodies}

The four mAbs all reacted in ELISA with outer membranes of strain MC50 and on Western blotting produced a broad band of molecular mass approximately $18.6 \mathrm{kDa}$. Since it was possible that the mAbs were directed against a single epitope, synthetic oligopeptides were used in an attempt to define the epitopes recognized by the mAbs. Decapeptides were synthesized, corresponding to the predicted amino acid sequence of the Lip antigen, and incorporating the changes observed in the consensus sequence (Baehr et al., 1989). The oligopeptides were assayed for immunological reactivity with each of the anti-Lip mAbs. In each case reactivity was
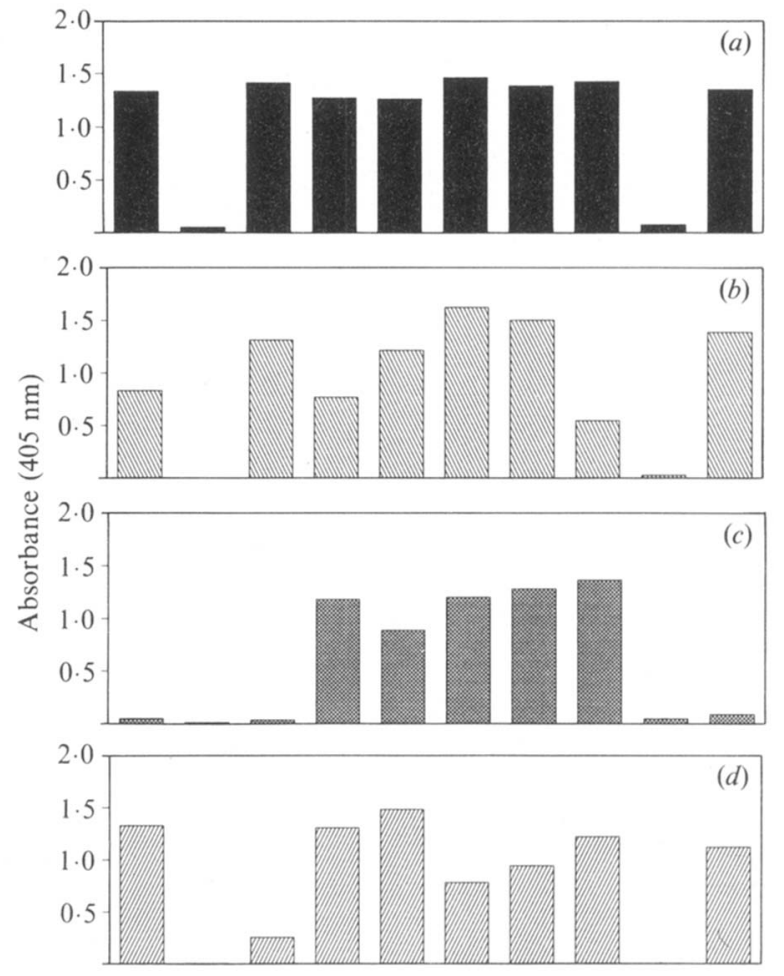

$\begin{array}{llllllllll}\text { K } & \mathbf{P} & \text { S } & \text { P } & \text { A } & \text { A } & \text { E } & \text { A } & \text { P } & \text { A } \\ \text { A } & \text { A } & \text { S } & \text { A } & \text { A } & \text { E } & \text { A } & \text { P } & \text { A } & \text { A } \\ \text { A } & \text { A } & \text { T } & \text { A } & \text { E } & \text { A } & \text { P } & \text { A } & \text { A } & \text { A } \\ \text { E } & \text { E } & \text { E } & \text { E } & \text { A } & \text { P } & \text { A } & \text { A } & \text { E } & \text { E } \\ \text { A } & \text { A } & \text { A } & \text { A } & \text { P } & \text { A } & \text { A } & \text { E } & \text { A } & \text { A } \\ \text { P } & \text { S } & \text { P } & \text { P } & \text { A } & \text { A } & \text { E } & \text { A } & \text { A } & \text { P } \\ \text { A } & \text { S } & \text { A } & \text { A } & \text { A } & \text { E } & \text { A } & \text { P } & \text { A } & \text { A } \\ \text { A } & \text { T } & \text { A } & \text { A } & \text { E } & \text { A } & \text { P } & \text { A } & \text { T } & \text { A } \\ \text { E } & \text { E } & \text { E } & \text { E } & \text { A } & \text { P } & \text { A } & \text { A } & \text { E } & \text { E } \\ \text { A } & \text { A } & \text { A } & \text { A } & \text { P } & \text { A } & \text { A } & \text { E } & \text { A } & \text { A }\end{array}$

Fig. 1. Localization of epitopes recognized by anti-H. 8 mAbs. A series of solid-phase decapeptides corresponding to the predicted amino acid composition of Lip antigen (Baehr et al., 1989) were reacted in ELISA with mAbs SM70 (a), SM71 (b), SM72 (c) and SM73 (d).

detected with a number of peptides corresponding to different regions of the Lip antigen and significant differences in reactivity of the individual mAbs could be observed (Fig. 1). Antibodies SM70 and SM71 reacted with all peptides containing the sequence EAPAAE, SM73 reacted with only a limited subset of these peptides, and SM72 reacted only with peptides containing the sequence PAAEAP. These data were not sufficient to define the minimum specificities of the antibodies, but since the recognized sequences all lay within the consensus repeating sequence, a further set of peptides based on this sequence were synthesized.

A series of overlapping decapeptides were synthesized, based on the consensus sequence, with adjacent peptides differing by a single amino acid residue. Similar sets of octamers, heptamers, hexamers, tetramers and trimers were also synthesized. Each $\mathrm{mAb}$ produced a distinctive pattern of reactivity with the peptides, which 

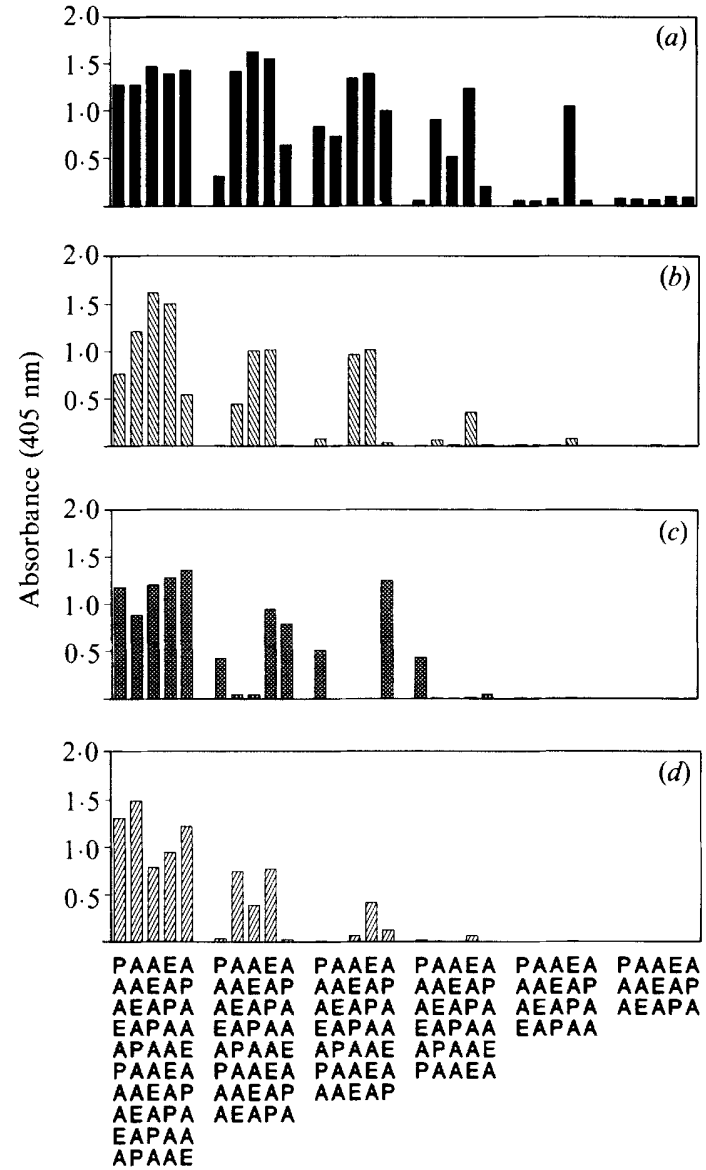

Fig. 2. Definition of epitopes recognized by anti-Lip mAbs. A series of overlapping peptides, based on the consensus repeating sequence, were synthesized on solid-phase supports with adjacent peptides differing by a single amino acid residue. The peptides were reacted in ELISA with mAbs $\operatorname{SM70~(a),~SM71~(b),~SM72~(c)~and~} \operatorname{SM73(d).~}$

permitted definition of the different epitopes recognized (Fig. 2). Thus the minimum epitope recognized by $\mathrm{mAb}$ SM70 was the tetrapeptide EAPA since all longer peptides reactive with SM70 contained this sequence whilst those that did not were non-reactive. Similarly the minimum epitopes recognized by $\mathrm{mAbs}$ SM 71 and SM72 could be defined as EAPAAE and PAAEAP respectively. The minimum epitope recognized by SM73 could be defined as (A)EAPAAE(A), requiring an alanine residue at one or both ends of the peptide for optimal reactivity.

\section{Purification of a meningococcal Lip antigen by affinity chromatography}

To examine the polyclonal immune response to Lip required a source of purified antigen. Preliminary experiments using selective extraction, gel filtration and ion-exchange chromatography (Strittmatter \& Hitchcock, 1986; Zollinger et al., 1985) produced only low yields of impure material. The availability of specific anti-Lip mAbs was therefore used in an affinity purification of Lip antigen. Analysis of the fractions from the column (Fig. 3a) showed that virtually all of the protein detected passed directly through the column (fractions 3-4). The Lip antigen profile, measured by dot-blot assay, revealed low levels of antigen in the initial fractions and that specific elution occurred on application of the $\mathrm{NaCl} / \mathrm{NH}_{4} \mathrm{OH}$ (fractions 11-12). SDSPAGE analysis of the fractions showed that whole-cell protein was confined to fractions 3-4 but no protein was detected by PAGE-Blue staining in the tracks containing specifically desorbed Lip antigen. On silver staining using the method of Hitchcock \& Brown (1983) a weak yellow/green band corresponding to the expected $18.6 \mathrm{kDa}$ position of the Lip antigen could be seen on overloaded gels (Fig. $3 b$ ). On Western blots this band reacted strongly with mAb SM70. A similar band was also observed on blots which were reacted with rabbit antisera raised against complete outer membranes from the same strain; in this case no other bands were detected, confirming the purity of the antigen preparation (Fig. 3c).

Amino acid analysis revealed that the purified antigen was rich in alanine, proline and glutamine or glutamate, and lacked sulphur-containing residues. The amino acid analysis also permitted quantification of the Lip antigen: the specifically eluted fractions contained $0.7 \mathrm{mg}$ protein, measured as total amino acids, and this represented an overall yield of $50 \%$ as measured by dot-blot assay. When $\mathrm{N}$-terminal amino acid sequence analysis was performed on the purified material no free amino terminus could be detected, as would be predicted with an amino-terminal-substituted lipoprotein.

\section{Production and characterization of polyclonal anti-Lip antisera}

Mice were injected intraperitoneally with $5 \mu \mathrm{g}$ purified Lip antigen adsorbed to $120 \mu$ l aluminium hydroxide gel, at intervals of two weeks. After four injections all mice showed the presence of specific anti-Lip antibodies, with a titre of $1-3 \times 10^{6}$ as measured by ELISA with purified antigen. No detectable antibodies were present in preimmune sera or in mice immunized with aluminium hydroxide alone. The immune sera also showed a significant, although lower, increase to a titre of $5 \times 10^{5}$ against outer membranes from strain MC50. However, despite the significant increases in ELISA titre, the sera showed no detectable reaction with Lip antigen on Western blotting with outer membranes from strain MC50. 

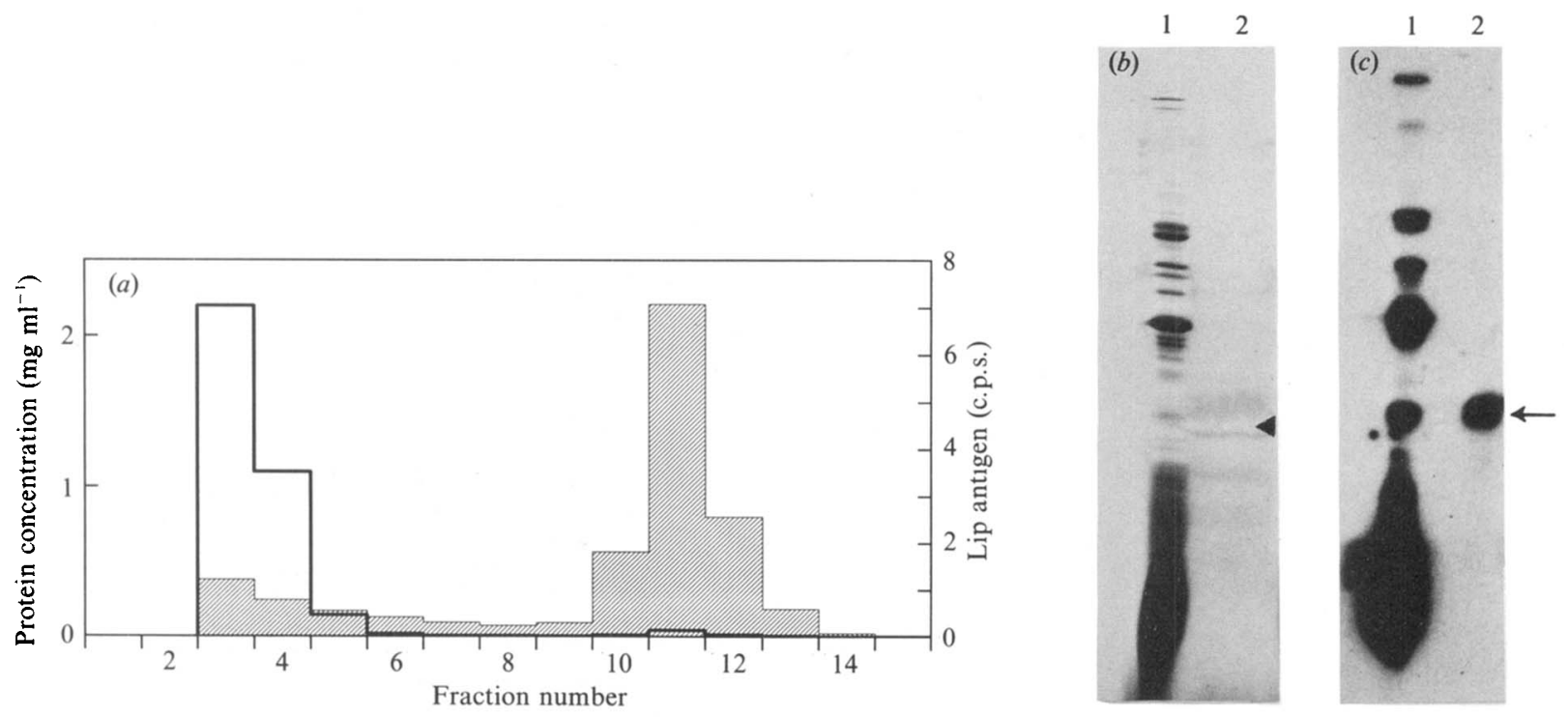

Fig. 3. Affinity purification of Lip from meningococcal strain MC50. Outer membranes were solubilized in RIP buffer and applied to an affinity column of mAb SM70 coupled to Sepharose CL-4B. The column was washed with RIP buffer then eluted with $0.5 \mathrm{M}-\mathrm{NaCl}$ $\mathrm{pH} \mathrm{11 \cdot 0.} \mathrm{(a)} \mathrm{Elution} \mathrm{profile} \mathrm{of} \mathrm{affinity} \mathrm{column.} \mathrm{The} \mathrm{hatched} \mathrm{area} \mathrm{represents} \mathrm{Lip} \mathrm{antigen} \mathrm{measured} \mathrm{by} \mathrm{dot-blot} \mathrm{assay;} \mathrm{the} \mathrm{bold} \mathrm{line}$ represents total protein measured by the bicinchoninic acid assay. (b) SDS-PAGE of affinity-purified antigen subjected to silver staining: 1 , outer-membrane preparation before affinity purification; 2 , purified antigen eluted by $0.5 \mathrm{M}-\mathrm{NaCl} \mathrm{pH} 11 \cdot 0$, (the arrowhead indicates the position of weakly staining band at $18.6 \mathrm{kDa}$ ). (c) Western blot of purified material using polyclonal antisera raised against outer membranes of strain MC50:1, outer-membrane preparation before affinity purification; 2 , purified antigen eluted by $0.5 \mathrm{M}-\mathrm{NaCl}$ $\mathrm{pH} 11 \cdot 0$.
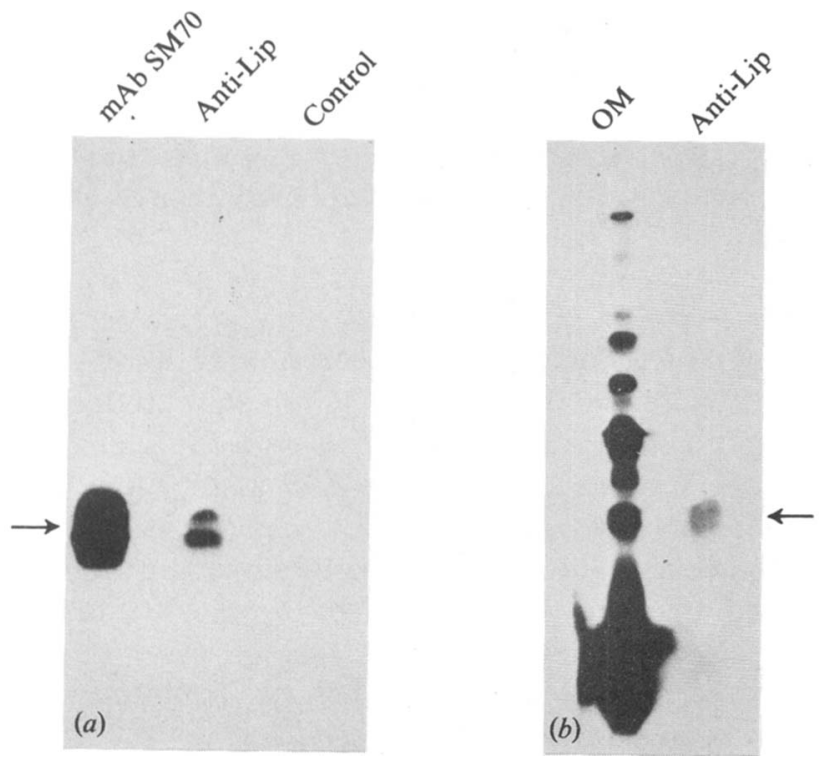

Fig. 4. Immune precipitation of Lip antigen by polyclonal antisera. Outer membranes of strain MC50 were solubilized in RIP buffer and incubated with polyclonal mouse antisera raised against the purified antigen. The immune complexes were recovered on Protein ASepharose and subjected to SDS-PAGE. (a) The precipitated antigens were detected by Western blotting. Tracks contained material immunoprecipitated using mouse polyclonal anti-H.8 (anti-Lip), a positive control precipitation carried out with mAb SM70, and control serum from a mouse immunized with adjuvant alone (control). The presence of Lip antigen was demonstrated by reacting the blot with
A possible explanation for the apparent discrepancy between the results of the ELISA and Western blotting experiments was that the antibodies induced by immunization with purified Lip recognized conformational rather than continuous epitopes on the antigen. Previous studies with meningococcal pili have demonstrated that such antibodies can be detected by immune precipitation of radiolabelled antigens under non-denaturing conditions (Diaz et al., 1984). Such experiments were not possible with the Lip antigen since preliminary experiments showed that it labelled very poorly by the method of Bolton \& Hunter (1973) and not at all using chemical oxidation. An alternative method of immunoprecipitation was devised which would detect anti-Lip antigen reactivity, despite the fact that it could not be radiolabelled. Immune precipitation was carried out using the mouse polyclonal anti-Lip sera and solubilized antigen from strain MC50. The precipitated material was then subjected to SDS-PAGE and the presence of Lip antigen was detected by Western blotting. The use of mAb SM70 confirmed the presence of Lip antigen in the immune

mAb SM70. (b) The immunological purity of the immune precipitate obtained with mouse polyclonal anti-Lip was assessed by Western blotting. Tracks contained immune precipitate (anti-Lip) and control outer-membrane preparation (OM). The presence of Lip and other outer-membrane antigens was demonstrated by reacting the blot with polyclonal antisera raised against outer membranes of strain MC50. 


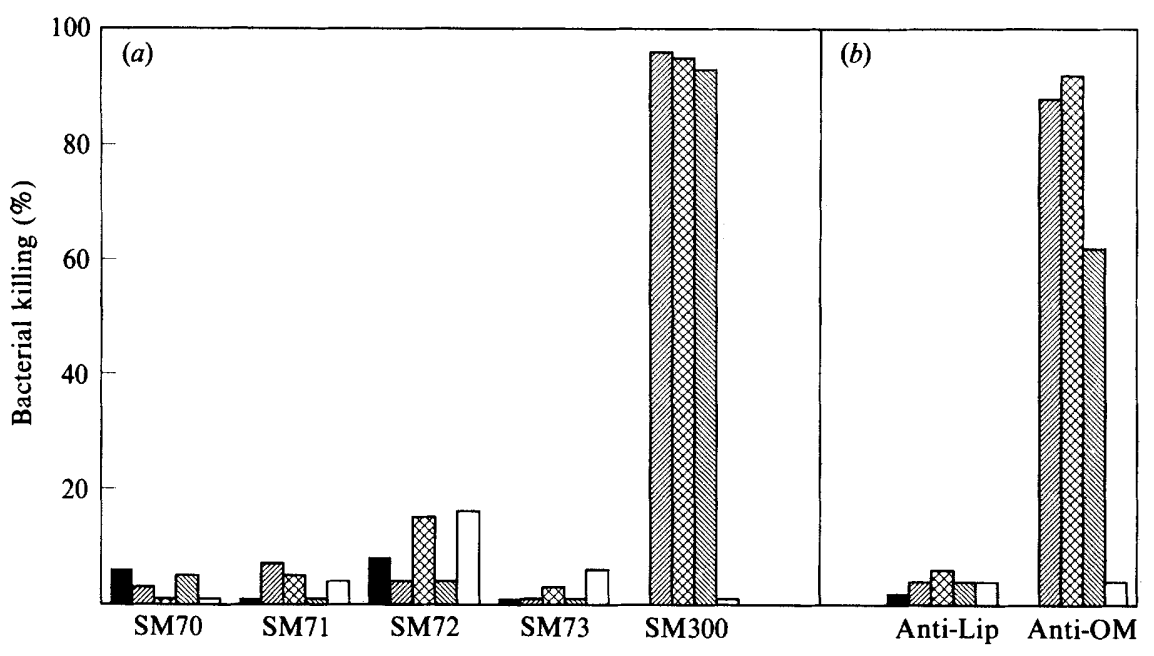

Fig. 5. Effect of anti-Lip antibodies in complementmediated bacterial killing experiments. (a) Effect of anti-Lip mAbs SM70, SM71, SM72 and SM73. The positive control antibody was SM300, directed against meningococcal class 1 outer-membrane protein. (b) Polyclonal antisera raised against purified Lip antigen (anti-Lip); control polyclonal antiserum was raised against outer membranes of strain MC50 (anti-OM). The concentrations of antibodies used were $1: 20=1: 100$ खाय $1: 500$, 1:2500 , and a control lacking antibody $\square$. precipitate obtained with the anti-Lip sera (Fig. 4a). A control immune precipitation reaction carried out with mAb SM70 itself also precipitated Lip antigen but no bands were detected in precipitates with serum from mice immunized with aluminium hydroxide alone.

In a second experiment to investigate the specificity of the immune response to the Lip antigen the immune precipitate obtained with the anti-Lip sera was subjected to Western blotting using rabbit anti-outer-membrane serum as the detection system. A single band corresponding to Lip antigen was detected (Fig. $4 b$ ), thus confirming that the immune response to the purified Lip antigen was specific for the antigen and directed mainly against conformational and not linear epitopes.

\section{In vitro, complement-mediated bactericidal assays}

The four mAbs were investigated to determine whether they were capable of activating complement-mediated bacteriolysis. No bactericidal effect was observed with any of the antibodies, in contrast with a positive control directed against class 1 protein, which killed over $90 \%$ of the bacteria at similar concentrations of antibody (Fig. 5). Similarly the polyclonal mouse anti-Lip antiserum was tested for its ability to promote complement bactericidal killing of strain MC50. No significant bactericidal effect could be detected at a range of dilutions tested, in contrast to results obtained with antisera raised against outer membranes of the same strain (Fig. 5).

\section{Discussion}

The conserved nature of the Lip antigen and its occurrence in pathogenic but not non-pathogenic
Neisseria species has focused attention on its potential for immunization against meningococcal infection. The Lip antigen is highly immunogenic both during natural infection and on immunization of laboratory animals. Indeed it was this latter property that led to its identification with the advent of mAb studies (Cannon $e t$ al., 1984; Zollinger et al., 1985; Virji et al., 1985) since previous studies had failed to detect the antigen because of its inability to stain following SDS-PAGE. Cloning and sequencing of the lip gene from two gonococcal strains has revealed a predicted lipoprotein structure comprising 13 or 14 imperfect repeats of a consensus pentapeptide AAEAP and with an N-terminal cystine substituted by lipid (Woods et al., 1989; Baehr et al., 1989).

The nature of the structure of the Lip antigen with its multiple repeats of a consensus pentapeptide suggests that it must contain only a very limited number of distinct potential antigenic determinants. Indeed it seemed possible that diverse $\mathrm{mAbs}$ with Lip specificity might be restricted to recognition of a single determinant. However, the ability to synthesize large numbers of peptides on solid-phase supports now permits the detailed mapping of epitopes recognized by mAbs. Using the consensus repeat sequence for epitope mapping revealed that each of the $\mathrm{mAbs}$ used in these studies recognized distinct overlapping epitopes.

The availability of $\mathrm{mAbs}$ also permitted affinity purification of the Lip antigen. Previous studies have purified Lip antigen by selective extraction followed by a combination of ion-exchange and size-exclusion chromatography (Strittmatter \& Hitchcock, 1986; Bhattacharjee et al., 1988). In the current study similar methods produced low yields of antigen contaminated by significant amounts of other outer-membrane components. In contrast, the use of mAb SM70 in affinity chroma- 
tography produced antigen containing no impurities which could be detected by silver staining. The amino acid composition of the purified Lip antigen was in accord with previous studies (Strittmatter \& Hitchcock, 1986; Bhattacharjee et al., 1988) in that it showed an abundance of alanine, glutamate and proline.

The purity of the antigen was also supported by the failure to detect, in antisera raised against it, antibodies to other meningococcal components either by Western blotting or on immune precipitation. The failure of the anti-Lip to react with the antigen itself in Western blots, in contrast to its reactivity in immune precipitation, demonstrated that the predominant immune response was directed against conformational rather than continuous epitopes. This specificity is distinct from that of the $\mathrm{mAbs}$ which have been obtained following immunization with meningococci or outer membranes (Cannon et al., 1984; Zollinger et al., 1985; Virji et al., 1985), a situation which may result from the fact that Western blotting is the method generally used to determine the specificity of hybridoma. Certainly the predominance of conformation-dependent antibodies in the polyclonal sera would be in accord with the predicted structure of the Lip antigen. Secondary sequence analysis based on the inferred amino acid sequences from the gonococcal strains predicts an entirely alpha-helical structure (Woods et al., 1989; Baehr et al., 1989) and comparison with other bacterial proteins containing multiple repeat sequences suggests a quaternary structure comprising an alpha-helical coiled coil (McLachlan, 1978; Phillips et al., 1981).

Despite the conserved nature of the Lip antigen and the association of its expression with virulence in Neisseria, the evidence of its ability to induce a protective immune response is contradictory. Initial studies reported that an anti-Lip $\mathrm{mAb}$ produced passive protection in an infant mouse model of meningococcal infection. but subsequent studies suggested that the observed protection was due to non-specific immune stimulation by contaminating LPS (Woods et al., 1987). It is generally accepted that since the presence of serum bactericidal activity correlates with immunity to meningococcal disease (Goldschneider et al., 1969) the most desirable attribute of potential vaccine candidates is the ability to induce antibodies which promote complement-mediated bactericidal killing. In a study of gonococcal strains Schweinle et al. (1989) reported that one anti-Lip mAb was bactericidal for two strains while Bhattacharjee et al. (1990), using another $\mathrm{mAb}$, found no killing of three different meningococcal strains tested. Given the highly conserved and repetitive structure of the Lip antigen it initially seemed likely that the mAbs used in such experiments might be directed against a single immunodominant epitope. However, the mAbs used in the present study were shown to recognize distinct structural motifs based on the consensus repeat sequence, while the polyclonal sera produced by immunization with purified antigen recognized conformational epitope(s) on the antigen. Despite the diversity of epitopes recognized, none of the antibodies showed significant bactericidal activity.

The reason for the failure of anti-Lip antibodies to promote bacterial killing is not clear but may be related to limited exposure of the antigen on the surface of meningococci. Initial studies suggested that Lip antigen was readily accessible on the surface of gonococci (Hitchcock et al., 1985) but more recent studies using immune electron microscopy suggest that the antigen may only be accessible on approximately $20 \%$ of gonococci in urethral exudates (Robinson et al., 1987). For whatever reason, the results in the current study suggest that despite its initial apparent promise as a potential vaccine candidate, the case for the inclusion of Lip antigen in vaccine formulation cannot be supported at present, although it should be noted that the immune reponse in humans may be different to that of laboratory animals.

\section{References}

BaeHr, W., Gotschlich, E. C. \& HitchCock, P. J. (1989). The virulence-associated gonococcal $\mathrm{H} .8$ gene encodes 14 tandemly repeated pentapeptides. Molecular Microbiology 3, 49-55.

Bhattacharjee, A. K., Moran, E. E., Ray, J. S. \& Zollinger, W. D. (1988). Purification and characterisation of the H.8 antigen from group B Neisseria meningitidis. Infection and Immunity 56, 773-778.

Battacharjee, A. K., Moran, E. E. \& Zollinger, W. D. (1990). Antibodies to meningococcal H.8 (Lip) antigen fail to show bactericidal activity. Canadian Journal of Microbiology 36, 117-122.

BLACK, J. R. \& CANNON, J. G. (1984). Monoclonal antibody (McAb) to common pathogenic Neisseria antigen $(\mathrm{H} 8 \mathrm{Ag}$ ) protects against meningococcemia in mice. Abstracts of the 24th Interstate Conference on Antimicrobial Agents and Chemotherapy, abstract 96. Washington DC: American Society for Microbiology.

BlaCK, J. R., BLACK, W. J. \& CANNON, J. G. (1985). Neisserial antigen $\mathrm{H} .8$ is immunogenic in patients with disseminated gonococcal and meningococcal infections. Journal of Infectious Diseases 151, 650-657.

Bolton, A. E. \& Hunter, W. M. (1973). The labelling of proteins to high specific radioactivities by conjugation to a ${ }^{125}$ I-containing acylating agent. Application to the radioimmunoassay. Biochemical Journal 133, 529-539.

Cannon, J. G., Black, W. J., Nachamkin, I. \& Stewart, P. W. (1984). Monoclonal antibody that recognises an outer membrane antigen common to the pathogenic Neisseria species but not to most nonpathogenic Neisseria species. Infection and Immunity 43, 994-999.

DIAZ, J.-L., VIRJ, M. \& HeCKeLS, J. E. (1984). Structural and antigenic differences between two types of meningococcal pili. FEMS Microbiology Letters 21, 181-184.

Fairbanks, G., Steck, T. L. \& Wallach, D. F. H. (1971). Electrophoretic analysis of the major polypeptides of the human erythrocyte membrane. Biochemistry 10, 2606-2617.

Frasch, C. E., Zollinger, W. D. \& Poolman, J. T. (1985). Serotype antigens of Neisseria meningitidis and a proposed scheme for designation of serotypes. Reviews of Infectious Diseases 7, 504-510. 
Gold, R., Lepow, M. L., Goldschneider, I., Draper, T. F. \& GoTsCHLICH, E. C. (1979). Kinetics of antibody production to group $\mathrm{A}$ and group $\mathrm{C}$ meningococcal polysaccharide vaccines administered during the first six years of life: prospects for routine immunization of infants and children. Journal of Infectious Diseases 140, 690697.

GoldsChneider, I., Gotschlich, E. C. \& Artenstein, M. S. (1969). Human immunity to the meningococcus. II. Development of natural immunity. Journal of Experimental Medicine 129, 1327-1348.

HECKELS, J. E. (1981). Structural comparison of Neisseria gonorrhoeae outer membrane proteins. Journal of Bacteriology 145, 736-742.

HITCHCOCK, P. J. (1989). Unified nomenclature for pathogenic Neisseria species. Clinical Microbiology Reviews 2, S64-S65.

Hitchсоск, P. J. \& Brown, T. M. (1983). Morphological heterogeneity among Salmonella lipopolysaccharide chemotypes in silverstained polyacrylamide gels. Journal of Bacteriology 154, 269-277.

HitchCock, P. J., HaYes, S. F., Mayer, L. W., Shafer, W. M. \& TESSIER, S. L. (1985). Analyses of gonococcal H.8 antigen. Surface location, inter- and intra-strain electrophoretic heterogeneity, and unusual two-dimensional electrophoretic characteristics. Journal of Experimental Medicine 162, 2017-2034.

Kawula, T. H., Spinola, S. M., Klapper, D. G. \& Cannon, J. G. (1987). Localisation of a conserved epitope and an azurin-like domain in the H.8 protein of pathogenic Neisseria. Molecular Microbiology 1, 179-185.

KHYSE-ANDERSEN, J. (1984). Electroblotting of muitiple gels: a simple apparatus without buffer tank for rapid transfer of proteins from polyacrylamide to nitrocellulose. Journal of Biochemical and Biophysical Methods 10, 203-209.

McGuinness, B. T., Clarke, I. N., Lambden, P. R., Barlow, A. K., Poolman, J. T., Jones, D. M. \& Heckels, J. E. (1991). Point mutation in meningococcal por $A$ gene associated with increased endemic disease. Lancet 337, 514-517.

McLachlan, A. D. (1978). The double helix coiled coil structure of murein lipoprotein from Escherichia coli. Journal of Molecular Biology 122, 493-506.

Munkley, A., Tinsley, C. R., VirJi, M. \& Heckels, J. E. (1991). Blocking of bactericidal killing of Neisseria meningitidis by antibodies directed against class 4 outer membrane protein. Microbial Pathogenesis 11, 447-452.

Peltola, H. (1983). Meningococcal disease: still with us. Reviews of Infectious Diseases 5, 71-91.

Peltola, H., Safary, A., Kayhty, H., Karanko, V. \& Andre, F. E. (1985). Evaluation of two tetravalent $\left(\mathrm{ACYW}_{135}\right)$ meningococcal vaccines in infants and small children: a clinical study comparing immunogenicity of $O$-acetyl-negative and $O$-acetyl-positive group C polysaccharides. Pediatrics 76, 91-96.

Phillips, G. N., Flicker, P. F., Cohen, C., Manjula, B. N. \& FisChETTI, V. A. (1981). Streptococcal M protein: $\alpha$-helical coiledcoil structure and arrangement on the cell surface. Proceedings of the National Academy of Sciences of the United States of America 78, 4689-4693.

Poolman, J. T., de Marie, S. \& Zanen, H. C. (1980). Variability of low-molecular-weight, heat-modifiable outer membrane proteins of Neisseria meningitidis. Infection and Immunity 30, 642-648.

Poolman, J. T., Hopman, C. T. P. \& Zanen, H. C. (1983). Immunogenicity of meningococcal antigens as detected in patient sera. Infection and Immunity 40, 398-406.

Reingold, A. L., Broome, C. V., Hightower, A. W., Ajelo, G. W., Bolan, G. A., Adamsbaum, C., Jones, E. E., Phillips, C., Tiendrebeogo, H. \& Yada, A. (1985). Age-specific differences in duration of clinical protection after vaccination with meningococcal polysaccharide A vaccine. Lancet 2, 114-118.

Robinson, E. N., McGee, Z. A., Buchanan, T. M., Blake, M. S. \& HITCHCOCK, P. J. (1987). Probing the surface of Neisseria gonorrhoeae: simultaneous localisation of PI and H.8 antigens. Infection and Immunity 55, 1190-1197.

Schweinle, J. E., Hitchcock, P. J., Tenner, A. J., Hammer, C. H., FrANK, M. M. \& JoINER, K. A. (1989). Interaction of Neisseria gonorrhoeae with classical complement components, C1-inhibitor, and a monoclonal antibody directed against the neisserial H.8 antigen. Journal of Clinical Investigation 83, 397-403.

Smith, P. K., Krohn, R. I., Hermanson, G. T., Mallia, A. K., Gartner, F. H., Provenzano, M. D., Fujimoto, E. K., Goeke, N. M., OLSON, B. J. \& KLENK, D. C. (1985). Measurement of protein using bicinchoninic acid. Analytical Biochemistry 150, 76-85.

STRITTMATTER, W. \& HitchCOCK, P. J. (1986). Isolation and preliminary biochemical characterization of the gonococcal H.8 antigen. Journal of Experimental Medicine 164, 2038-2048.

TINSLEY, C. R. \& HECKELS, J. E. (1986). Variation in the expression of pili and outer membrane protein by Neisseria meningitidis during the course of meningococcal infection. Journal of General Microbiology 132, 2483-2490.

VIRJ, M. \& HECKELS, J. E. (1988). Nonbactericidal antibodies against Neisseria gonorrhoeae: evaluation of their blocking effect on bactericidal antibodies directed against outer membrane antigens. Journal of General Microbiology 134, 2703-2711.

VIRJI, M. \& HECKeLS, J. E. (1989). Location of a blocking epitope on outer membrane protein III of Neisseria gonorrhoeae by synthetic peptide analysis. Journal of General Microbiology 135, $1895-1899$

VIRI, M., ZAK, K. \& Heckels, J. E. (1985). Use of monoclonal antibodies to detect common protein antigens present in outer membranes of Neisseria species. In The Pathogenic Neisseriae: Proceedings of the Fourth International Symposium, pp. 276-280. Edited by G. K. Schoolnik. Washington DC: American Society for Microbiology.

VirJi, M., Fletcher, J. N., ZaK, K. \& HeCKels, J. E. (1987). The potential protective effect of monoclonal antibodies to gonococcal outer membrane protein IA. Journal of General Microbiology 133, 2639-2646.

WeDEGe, E. \& Froholm, L. O. (1986). Human antibody response to a group B serotype $2 \mathrm{~A}$ meningococcal vaccine determined by immunoblotting. Infection and Immunity 51, 571-578.

Woods, J. P., Black, J. R., BarRit, D. S., Connel, T. D. \& CanNon, J. G. (1987). Resistance to meningococcaemia apparently conferred by anti-H.8 monoclonal antibody is due to contaminating endotoxin and not to specific immunoprotection. Infection and Immunity 55, $1927-1928$.

Woods, J. P., Spinola, S. M., Strobel, S. M. \& Cannon, J. G. (1989). Conserved lipoprotein H.8 of pathogenic Neisseria consists entirely of pentapeptide repeats. Molecular Microbiology 3, 43-48.

ZaK, K., DiAZ, J.-L., JACKsON, D. \& HeCKels, J. E. (1984). Antigenic variation during infection with Neisseria gonorrhoeae: detection of antibodies to surface proteins in sera of patients with gonorrhoea. Journal of Infectious Diseases 149, 166-173.

Zollinger, W. D., Ray, J. S., Moran, E. E. \& Seid, R. (1985) Identification by monoclonal antibody of an antigen common to the pathogenic Neisseria species. In The Pathogenic Neisseriae: Proceedings of the Fourth International Symposium, pp. 579-584. Edited by G. K. Schoolnik. Washington DC: American Society for Microbiology. 